\title{
EDUCAÇÃO ESCOLAR EM COMUNIDADES QUILOMBOLAS DO TERRITÓRIO DE IDENTIDADE DO VELHO CHICO-BA
}

\author{
Dinalva de Jesus Santana Macêdo (UNEB)* \\ Marcos Luciano Lopes Messeder (UNEB)** \\ Delcele Mascarenhas Queiroz (UNEB)***
}

\begin{abstract}
RESUMO
Este artigo visa apresentar algumas reflexões a partir de uma pesquisa de doutorado realizada em três escolas, situadas em comunidades quilombolas do município de Bom Jesus da Lapa-BA, no Território de Identidade do Velho Chico. Buscamos analisar de que modo a educação escolar dialoga com as especificidades étnicoculturais das comunidades quilombolas. Para a coleta de dados, utilizamos entrevistas semiestruturadas com professores, gestores, coordenadora pedagógica, pais e lideranças quilombolas, grupos focais com os alunos, análises dos projetos político-pedagógicos das escolas, observações de eventos, registros fotográficos e anotações em diário de campo. Os resultados demonstram que as escolas tratam as especificidades étnico-culturais das comunidades quilombolas de maneira pontual, descontextualizada e superficial, em datas comemorativas, no componente curricular de história, gincanas e outros eventos. Todavia, constatamos algumas experiências pedagógicas significativas que vêm transgredindo os currículos escolares para dialogar com o universo sociocultural dos alunos.

Palavras-chave: Educação escolar quilombola. Práticas curriculares. Relações étnicoraciais. Interculturalidade.
\end{abstract}

\section{ABSTRACT \\ SCHOOL EDUCATION IN QUILOMBOLAS COMMUNITIES OF THE OLD CHICO IDENTITY TERRITORY-BA}

This article aims to present some reflections from a doctoral research carried out in three schools, located in quilombola communities of the municipality of Bom Jesus da Lapa-BA, in the Identity Territory of Velho Chico. We seek to analyze how school education dialogues with the ethnic-cultural specificities of the quilombola communities. For the data collection, we used semi- leaders, focus groups with students, analyzes of political pedagogical projects of schools, observations of events, photographic records and notes in field diaries. The results structured interviews with

* Doutora em Educação pela Universidade do Estado da Bahia (PPGEDUC/UNEB). Professora Adjunta da UNEB. E-mail: dinalvamacedo@hotmail.com

** Doutor em Sociologia e Antropologia pela Universidade Lumière Lyon 2 - França. Professor Adjunto do Departamento de Educação da UNEB. E-mail: marmesseder21@gmail.com

*** Doutora em Educação pela Universidade Federal da Bahia (UFBA). Professora Titular da UNEB. E-mail: dmqueiroz@uol. com.br 
teachers, managers, pedagogical coordinators, parents and quilombola show that the schools treat the ethnic-cultural specificities of quilombola communities in a punctual, decontextualized and superficial way, in commemorative dates, in the curricular component of history, gymkhana and other events. However, we have observed some significant pedagogical experiences that have transgressed the school curricula to dialogue with the socio-cultural universe of the students.

Keywords: Quilombola school education. Curricular practices. Ethnic-racial relations. Interculturality.

\section{RESUMEN}

\section{EDUCACIÓN ESCOLAR EN COMUNIDADES QUILOMBOLAS DEL TERRITORIO DE IDENTIDAD DEL VIEJO CHICO-BA}

Este artículo pretende presentar algunas reflexiones a partir de una investigación de doctorado realizada en tres escuelas, situadas en comunidades quilombolas del municipio de Bom Jesus da Lapa-BA, en el Territorio de Identidad del Viejo Chico. Buscamos analizar de qué modo la educación escolar dialoga con las especificidades étnico-culturales de las comunidades quilombolas. Para la recolección de datos utilizamos entrevistas semiestructuradas con profesores, gestores, coordinadora pedagógica, padres y líderes quilombolas, grupos focales con los alumnos, análisis de los proyectos políticos pedagógicos de las escuelas, observaciones de eventos, registros fotográficos y anotaciones en diario de campo. Los resultados demuestran que las escuelas tratan las especificidades étnico-culturales de las comunidades quilombolas de manera puntual, descontextualizada y superficial, en fechas conmemorativas, en el componente curricular de historia, gincanas y otros eventos. Sin embargo, constatamos algunas experiencias pedagógicas significativas que vienen transgrediendo los currículos escolares para dialogar con el universo sociocultural de los alumnos.

Palabras clave: Educación escolar quilombola. Prácticas curriculares. Relaciones étnico-raciales. Interculturalidad.

\section{Introdução}

Com a Lei $\mathrm{n}^{\mathrm{o}}$ 10.639, de 09 de janeiro de 2003, que institui a obrigatoriedade do ensino de História e Cultura Afro-Brasileira e Africana nos estabelecimentos de Ensino Fundamental e Médio, das escolas públicas e particulares brasileiras (BRASIL, 2003), alterada pela Lei $n^{\circ} 11.645$, de 10 de março de 2008, que acrescenta a obrigatoriedade da História e Cultura Indígena nos currículos da educação básica (BRASIL, 2008), as instituições escolares são convocadas a trabalharem com a diversidade cultural, tendo em vista incluir nas práticas pedagógicas as culturas e as histórias que foram silenciadas e subalternizadas pelas políticas educacionais brasileiras.
Nesse sentido, ensinar a história do negro e dos povos indígenas na escola brasileira é romper com a visão eurocêntrica que exclui outras raízes culturais formadoras do Brasil como povo e nação (MUNANGA, 2014).

Diante desse contexto, os movimentos organizados pelas comunidades quilombolas passam a reivindicar uma educação escolar específica e diferenciada, que trabalhe a história, a cultura, os valores e os saberes tradicionais de suas comunidades. Eles lutam por uma educação que reinterprete a função social e política da escola (ARROYO, 2014). Como fruto dessas reivindicações, o Conselho Nacional de Educação e a Câmara de Edu- 
cação Básica, por meio do Parecer $\mathrm{CNE} / \mathrm{CEB} \mathrm{n}^{\circ}$ 16 (BRASIL, 2012a), aprova, em 05 de junho de 2012, as Diretrizes Curriculares Nacionais para a Educação Escolar Quilombola, as quais foram homologadas através da Resolução no 8 , de 20 de novembro de 2012. Esta Resolução, em seu art. $1^{\circ}$, define a educação escolar quilombola como uma modalidade específica da educação básica (BRASIL, 2012b).

É pertinente destacar que, em alguns estados brasileiros, iniciativas governamentais precederam a discussão nacional promovida por diferentes atores sociais, como professores, pesquisadores das universidades, movimento quilombola, dentre outros sujeitos, sobre políticas específicas para a educação escolar nos quilombos. Em 2007, o estado do Mato Grosso começa o debate sobre esta questão, conseguindo, em 2010, elaborar as orientações para a educação escolar para as comunidades quilombolas. O Estado do Paraná, em 2006, através de ações públicas promovidas pelo Grupo de Trabalho Clóvis Moura (GTCM), inicia o levantamento das demandas atinentes à educação escolar quilombola; todavia, só em 2010 aprova uma proposta pedagógica para a educação quilombola (CRUZ, 2012).

Em 2009, o município de Santarém, no estado do Pará, aprovou uma Resolução que assegura em lei a efetivação de políticas públicas educacionais para os quilombolas, tendo como prioridade a contratação de professores quilombolas para lecionarem em escolas situadas nessas comunidades.

A Bahia foi o terceiro estado a propor a elaboração das Diretrizes Curriculares para a Educação Escolar Quilombola; porém, devido à falta de recursos e morosidade do estado, essas Diretrizes Curriculares só foram elaboradas em 2013, perdendo a oportunidade de sair na frente das Diretrizes Nacionais (OLIVEIRA, 2013).

As Diretrizes para a Educação Escolar Quilombola do Estado da Bahia foram aprovadas pelo Conselho Estadual de Educação e pela Câmara de Educação Básica (CEE/CEB) através da Resolução $\mathrm{n}^{\mathrm{o}} 68$, de 30 de julho de 2013, e homologadas pelo Secretário do Estado de Educação da Bahia em 18 de dezembro de 2013, publicada no Diário Oficial em 20 de dezembro de 2013 (BAHIA, 2013).

Frente a essas demandas, o currículo escolar das escolas quilombolas deverá articular os co- nhecimentos tradicionais dos quilombolas com os conhecimentos escolares, sem hierarquização. Isso requer diálogo entre a gestão das escolas, professores, coordenação pedagógica, as comunidades e suas lideranças locais (BRASIL, 2012a). Além de uma clara concepção do que seja uma educação intercultural, pois a cultura precisa ser compreendida como processo dinâmico, engendrado por relações as mais diversas e, por isso mesmo, contraditórias, complementares, complexas. A cultura envolve as condições objetivas da vida, mas também os sentimentos, emoções e representações que se tem sobre o que é vivido. Assim, o que a cultura diz e o que está em jogo não são as diferenças, mas a alteridade que constitui nosso mundo. Ou seja, as relações que nos constituem enquanto um nós coletivo (GUSMÃO, 2011).

Tomando como referência essa problemática, a questão central da tese ${ }^{1}$ tratou de indagar se as especificidades étnico-culturais das comunidades quilombolas seriam contempladas nas práticas curriculares das escolas. Realizamos uma pesquisa de abordagem qualitativa, que teve como interlocutores professores, alunos, gestores, uma coordenadora pedagógica, os pais e as lideranças quilombolas locais. Esta perspectiva de pesquisa toma as interações cotidianas e o cenário ambiental e sociocultural no qual elas se desenrolam.

Com base nos princípios da etnografia, recorremos para a coleta de dados a entrevistas semiestruturadas, grupo focal, análise de documentos, observação participante, registros fotográficos e anotações em diário de campo. Portanto, não se trata de uma pesquisa etnográfica em sentido estrito, mas de um estudo que tem um viés etnográfico, com enfoque socioantropológico.

A pesquisa de campo foi realizada de abril a junho de 2013 em três escolas: a Escola Municipal Araçá Cariacá, situada na Comunidade Quilombola de Araçá Cariacá; a Escola Municipal Quilombola Emiliano Joaquim Vilaça e a Escola Municipal Elgino Nunes de Souza, localizadas respectivamente nas comunidades de Brasileira e Rio das Rãs I, pertencentes ao Quilombo Rio das Rãs. Essas comunidades estão localizadas no município de

1 Educação em Comunidades Quilombolas do Território de Identidade do Velho Chico-BA: indagações acerca do diálogo entre as escolas e as comunidades locais (MACÊDO, 2015). 
Bom Jesus da Lapa, no Território de Identidade do Velho Chico-BA/Brasil, que dista a $773 \mathrm{~km}$ da capital baiana, Salvador.

Os resultados revelam que as escolas trabalham as especificidades étnico-culturais das comunidades de maneira pontual e superficial, em datas comemorativas, no componente curricular de história, gincanas e outros eventos. Todavia, constatamos algumas experiências significativas para além do componente curricular de história de professoras que vêm transgredindo os currículos para dialogar com os conteúdos culturais e históricos das comunidades.

\section{As práticas curriculares e o trabalho com as especificidades locais}

A educação é um fenômeno complexo que não pode ser estudado sem levar em consideração os aspectos políticos, econômicos, culturais e sociais que estão imbricados no processo. Nesse sentido, corroborando com Amorim e Batista Neto (2011), compreendemos que as práticas curriculares são as ações desenvolvidas para a constituição do que denominamos currículo escolar, entendido não simplesmente como um conjunto de conteúdos formalmente estabelecidos, mas que se configura em diferentes saberes, conflitos, tramas e contradições, que se alimentam e retroalimentam cotidianamente. E o currículo se traduz em atividades e ganha significados através das práticas pedagógicas (SACRISTÁN, 1999). Assim sendo, em consonância com Costa (2005, p. 61), entendemos o currículo escolar como

[...] um texto que pode nos contar muitas histórias: histórias sobre indivíduos, grupos, sociedades, culturas, tradições; histórias que pretendem nos relatar como as coisas são ou como deveriam ser. O que há de comum entre elas é uma vontade de saber que, como assinala Foucault (1996), é inseparável da vontade de poder, e tem se constituído em 'prodigiosa maquinaria destinada a excluir' (p. 20). Na política cultural, essas representações construídas pelos discursos vão posicionando os indivíduos numa certa geografia e economia do poder cujo objetivo é o governo, a regulação social. Contudo, como nos alertou Said (1995), parece que entre os meandros das histórias para dominar sempre se cria um espaço para algum tipo de escape, alimentado por histórias de contestação e emancipação. Na esmagadora maioria dos casos, prossegue ele, a experiência histórica de resistência e insubordinação preponderou, inventando novos caminhos para narrativas de igualdade e solidariedade humana.

Nessa mesma direção, Arroyo (2011, p. 139) ressalta que o currículo é um território em disputa não simplesmente "[...] porque há temas a incluir nas disciplinas, mas a disputa é porque experiências e coletivos merecem ser reconhecidos, como produtores de conhecimentos legítimos, válidos". Diante disso, urge a descolonização do currículo escolar, por um currículo que tenha lugar para a ecologia de saberes ${ }^{2}$ ancorado por uma concepção crítica e emancipatória de educação e um modelo de gestão democrática, ${ }^{3}$ de maneira que a educação possa ser compreendida para além dos "muros" das escolas, pois esta acontece em diferentes espaços sociais e os professores não são os únicos agentes do saber que podem promovê-la (BRANDÃO, 2007).

A educação escolar quilombola compreende as escolas situadas nas comunidades quilombolas, bem como as escolas que atendem estudantes oriundos desses territórios (BRASIL, 2012a). Esta nova modalidade específica de educação exige que as práticas curriculares dialoguem com as culturas, as histórias e os saberes locais dos quilombolas.

As escolas nas quais trabalhamos atendem basicamente o público do ensino fundamental, totalizando 582 alunos e 25 professores, sendo 15 concursados e 10 contratados. Dentre os professores, apenas 10 residem nos quilombos. Todas as escolas têm salas multisseriadas, tanto no $1^{\mathrm{o}}$ Segmento do Ensino Fundamental, como no $2^{\circ}$ Segmento do Ensino Fundamental.

Dos 11 professores entrevistados, 05 são quilombolas e 06 são de outras localidades (Bom Jesus da Lapa, Riacho de Santana e Caetité). Dentre eles, 05 lecionam nos dois segmentos do Ensino Fundamental, 01 no $1^{\circ}$ Segmento do Ensino Fundamental

2 "É uma ecologia, porque se baseia no reconhecimento da pluralidade de conhecimentos heterogéneos (sendo um deles a ciência moderna) e em interações sustentáveis e dinâmicas entre eles sem comprometer a sua autonomia. A ecologia de saberes baseia-se na ideia de que o conhecimento é interconhecimento" (SANTOS, 2007, p. 22-23).

3 “Art. $39 \S 2^{\circ}$ A gestão das escolas quilombolas deverá ser realizada, preferencialmente, por quilombolas" (BRASIL, 2012b, p. $15)$. 
e 05 no $2^{\circ}$ Segmento do Ensino Fundamental. Esses professores têm entre um e quinze anos de experiência de magistério, com formação em Pedagogia, Geografia, Biologia, Letras, formação em magistério do ensino médio e formação geral. Dentre esses, um tem especialização em História e Cultura Afro-Brasileira e outro, especialização em Língua Portuguesa e Literatura Brasileira.

As equipes gestoras das escolas (diretoras, vice-diretores e coordenadora pedagógica) têm entre cinco e vinte anos de experiência de magistério. Esses gestores têm formação em magistério do ensino médio, licenciatura em Pedagogia, Normal Superior e Letras. Dentre esses, um com especialização em Psicopedagogia e Gestão e outro em Psicopedagogia, e um cursa especialização em Letras.

Os dados divulgados preservam o anonimato das identidades dos sujeitos. Os professores das três escolas, diretoras, vice-diretoras e coordenadora pedagógica foram designados como docente $1,2,3$ etc., seguido do nome da escola à qual estão vinculados.

Foi perceptível, durante a pesquisa, como a estrutura racista da sociedade brasileira se reproduz nesses espaços e dificulta a organização de uma instituição escolar orientada por um olhar de dentro. Mais adiante veremos como isso impede que as escolas sejam de fato geridas e organizadas a partir da lógica de uma educação comunitária diferenciada.

Posto isso, passaremos a apresentar algumas reflexões suscitadas pelos dados coletados nas entrevistas e conversas informais com os professores. Ao indagarmos os professores sobre como as escolas trabalham com os conhecimentos locais, os saberes tradicionais e as especificidades étnico-culturais das comunidades, encontramos as seguintes respostas: "Nós trabalhamos com esse conhecimento da história local, os saberes contados por Vitorino, ${ }^{4}$ a gente trabalha na sala de aula explicando dentro dos conteúdos possiveis [...] na disciplina de História [...]" (DOCENTE 1, Escola Municipal Araçá Cariacá, 10 de abril de 2013, grifo nosso). Outra professora acrescenta: "Aqui na escola, pelo menos quando eu trabalhei

4 Sr. Vitorino Pereira de Castro é um representante das gerações mais velhas da comunidade e guarda na memória muitas histórias de seus ancestrais. com a disciplina de História, foi bem voltada para a história da comunidade, até porque a escola cobrava muito e as lideranças também" (DOCENTE 3, Escola Municipal Araçá Cariacá, 12 de abril de 2013). Continua discorrendo a professora:

[...] O Sr. Florisvaldo já veio à escola várias vezes dar palestra, e como professora fui tentando entender pra passar para os alunos a história da comunidade [...]. A partir disso, houve duas gincanas, e a gente trabalhou nas gincanas também a história de Roque, ${ }^{5}$ houve até uma peça teatral [...] com a história de Roque, colocamos alguns alunos para apresentarem, então foi muito bonito. (DOCENTE 3, Escola Municipal Araçá Cariacá, 12 de abril de 2013, grifo nosso).

Em diálogo com professores de outra escola, assim se expressaram sobre o tema:

Seu Simplício é uma das lideranças que sempre a gente solicita para contribuir com seus saberes, uma pessoa de muita luta aqui na comunidade. [...] Então, ele tem um conhecimento muito amplo e sempre que é solicitado ele contribui com a nossa escola. (DOCENTE 2, Escola Municipal Quilombola Emiliano Joaquim Vilaça, 18 de maio de 2013, grifo nosso).

Trabalha como eu falei para você, aqui na comunidade tem a banda quilombo do professor Zezinho que fala sobre a cultura, o samba de roda, a capoeira. Tem um grupo dos próprios alunos que são dançarinos, então é por isso que a gente traz para a escola, para as culminâncias [dos trabalhos] (DOCENTE 3, Escola Municipal Quilombola Emiliano Joaquim Vilaça, 20 de maio de 2013).

\section{Continua com a narrativa:}

Uma das lideranças que preocupa com a educação é Wilson, ele falou que o professor que fosse trabalhar História dentro da comunidade tinha que falar sobre os quilombolas, sobre a história da comunidade. Então eu fui obrigada, quando eu cheguei aqui, porque eu não conhecia [a história] e pra falar sobre

5 Presume-se, com base na memória social, que a origem da comunidade de Araçá Cariacá está ligada à história de Roque Pereira de Castro, que nasceu no século XIX, por volta da década de (1830), o qual era escravo da família Castro e Tanajura, da cidade de Caetité, Bahia. Segundo a memória social, Roque foi vendido para a "mata de café" (São Paulo), resistiu para não ir: "morro, mas daqui não saio". Essa resistência praticada pelo ancestral está presente na memória dos quilombolas, que se reconhecem como filhos da terra, descendentes de Roque, numa estreita relação de parentesco, tendo este como o principal modelo de luta e resistência e de afirmação de suas identidades (MACÊDO, 2008). 
o quilombo eu fui pesquisar e foi a partir daí que a gente montou uma gincana pra falar sobre a história [...] (DOCENTE 3, Escola Municipal Quilombola Emiliano Joaquim Vilaça, 20 de maio de 2013).

É pertinente assinalar que o Centro Cultural do professor Zezinho, que inclui a banda quilombo, sob a sua coordenação, objetiva trabalhar para a preservação das tradições culturais e a afirmação da identidade étnico-racial dos quilombolas. Oferece atividades de música, dança, teatro capoeira, samba de roda para pessoas da comunidade, dentre as quais participam também alunos da escola. Todavia, não existem articulações das atividades desenvolvidas no Centro com as práticas pedagógicas. Quando se realiza algum evento cultural na escola, os professores colocam esses alunos para apresentarem alguma dança na culminância das atividades. Neste sentido, vemos que as práticas culturais como danças e músicas entram em cena como "alegorias" de um conteúdo curricular que, embora possa até referir estas produções, não as toma com sentidos pedagógicos em si mesmas, nem as examina no seu significado e importância cultural.

Vejamos os relatos dos professores de outra escola sobre o tratamento dessa temática:

A gente trabalha em sala fazendo debate, falando sobre o racismo, o preconceito, trabalha as culturas em gincana, o tema é voltado para a cultura da comunidade e em datas comemorativas [...] (DOCENTE 5, Escola Municipal Elgino Nunes de Souza, 10 de junho de 2013).

Os saberes tradicionais e as especificidades culturais são trabalhos mais em gincanas. A época da gincana é no mês de outubro, porque tá mais folgado para eles [os alunos] ensaiarem, [apresentam] dramatizações, o samba de roda e as coisas antigas da comunidade [...] (DOCENTE 1, Escola Municipal Elgino Nunes de Souza, 06 de junho de 2013, grifo nosso).

Quando eles [Chico de Helena e Manezim] vêm apresentarem na escola, os alunos acabam se envolvendo e participando. [...] Só que é assim: os alunos desenvolvem os trabalhos e os professores só para orientarem para não virar bagunça. [...] Esse trabalho é apresentado no pátio da escola, é uma gincana escolar. (DOCENTE 2, Escola Municipal Elgino Nunes de Souza, 06 de junho de 2013, grifo nosso).
Vemos, através das narrativas, que as escolas convidam as pessoas mais velhas e lideranças quilombolas locais (Florisvaldo, Sr. Vitorino, Simplício, Wilson, Chico de Helena e Manezim Canecão) para falarem sobre a história, a luta, os saberes tradicionais e as manifestações culturais das comunidades. É um procedimento metodológico importante para que educandos, professores, coordenadores pedagógicos e gestores das escolas conheçam a realidade sociocultural e histórica dessas comunidades. Contudo, essas atividades são realizadas nas escolas de forma pontual, através de gincanas, no componente de História, datas comemorativas, peças teatrais e palestras, o que pouco favorece para a construção de uma experiência de educação escolar quilombola que esteja em sintonia com a dinâmica sociocultural e histórica dos quilombolas.

Os docentes não discutem teórica e politicamente o sentido da História como narrativa de ordenação do passado, ou seja, como veremos a seguir, não é estranho que a história coletiva e subjetiva seja estigmatizada pela condição de escravo, como algo naturalizado, e o racismo envergonhe a vítima e a culpabilize.

Dando prosseguimento ao diálogo, os professores ressaltaram que os alunos não gostam de estudar os assuntos referentes à população negra e quilombola, o que dificulta o trabalho com essas questões nas escolas, como podemos destacar:

Quando a gente vai falar sobre a história [dos afrodescendentes e quilombolas], os meninos falam: 'Vai falar de novo sobre isso?' Eles não gostam muito, entendeu? [...] (DOCENTE 3, Escola Municipal Quilombola Emiliano Joaquim Vilaça, 20 de maio de 2013).

A aceitabilidade eu acho um pouco complicada, uns aceitam, outros não, a gente já ouviu relatos: 'Vêm de novo com esse assunto de negro [...]' (DOCENTE 5, Escola Municipal Araçá Cariacá, 24 de abril de 2013).

Podemos pensar acerca da resistência dos alunos remetendo-nos às declarações anteriores dos próprios professores, que dão conta de que a forma de trabalhar tais conteúdos não tem sido a mais estimulante. Isso, evidentemente, não se verifica apenas nessas escolas. A literatura tem apontado 
para esse aspecto, mostrando que as atitudes dos alunos podem estar relacionadas ao trabalho pedagógico mecânico, repetitivo e descontextualizado e à abordagem de História que é utilizada para trabalhar esses assuntos em salas de aula, como ilustram os depoimentos a seguir:

Eu fico muito triste quando a gente vai falar da cultura local. Eles [os alunos] acham que é um assunto muito batido. Eu não sei se é por conta da forma como a história dos negros foi passada para eles, ou se eles não gostam de falar [...] (DOCENTE 3, Escola Municipal Elgino Nunes de Souza, 06 de junho de 2013, grifo nosso).

Eu acho que alguns percebem como uma coisa distante, como uma coisa do passado [...] Mas a gente faz o trabalho e alguns participam com muita boa vontade, outros a gente tem que forçar a participação. (DOCENTE 5, Escola Municipal Araçá Cariacá, 24 de abril de 2013).

Essas narrativas nos dão pistas de que a História é trabalhada nas escolas numa sequência de tempo linear, evolucionista, baseada em episódios e eventos distantes da vida dos alunos. Além do mais, numa abordagem determinista e eurocêntrica dos fatos históricos, que desqualifica e ou invisibiliza as populações negras e quilombolas, o que certamente provoca a resistência dos alunos em relação a esses assuntos. Essas questões confirmam o que Santomé (2005) chama atenção, quando destaca que as salas de aula não podem continuar sendo espaços de memorização e veiculação de informações descontextualizadas.

$\mathrm{O}$ apego aos livros didáticos e ao conteudismo enumerativo e mnemônico são reflexos de professores que não se sentem autores de suas próprias prática pedagógicas. Uma perspectiva intercultural de educação suporia um processo radical de autorreflexão sobre as próprias concepções de educação, História, currículo, conhecimento, relações de poder, racismo e desigualdade. E estes professores, formados por currículos que não os autonomizaram, não podem se autorizar a crítica.

Nesse sentido, é preciso superar a perspectiva tradicional e eurocêntrica de educação, currículo e História, para dialogar com a realidade sociocultural das comunidades, bem como buscar materiais didáticos e metodologias dinâmicas e problema- tizadoras, para que os conhecimentos históricos e culturais sejam significativos e tenham sentido para os alunos.

Os professores reconhecem que o município de Bom Jesus da Lapa não tem uma proposta de educação específica para as comunidades quilombolas, pois o currículo oficial das escolas não é apropriado para essas populações; é um currículo "único", "imposto", homogêneo e uniformizado. No entanto, paradoxalmente, a Secretaria Municipal de Educação "cobra" das escolas que trabalhem com a realidade sociocultural das comunidades quilombolas. Os relatos ilustram essa informação:

O currículo escolar é único pra todas as escolas. $\mathrm{O}$ currículo da zona rural é o mesmo da cidade (DOCENTE 6, Escola Municipal Elgino Nunes de Souza, 10 de junho de 2013).

[O currículo da escola é] imposto sem discussão nenhuma [...] (DOCENTE 1, Escola Municipal Quilombola Emiliano Joaquim Vilaça, 17 de maio de 2013, grifo nosso).

[...] O currículo oficial não está apropriado para as comunidades quilombolas. [...] O professor, através do planejamento de ensino, busca uma aproximação com os conhecimentos da comunidade, especificamente em eventos. Mas há uma cobrança por parte da Secretaria que trabalhe com a realidade da comunidade quilombola. (DOCENTE 1, Escola Municipal Araçá Cariacá, 10 de abril de 2013, grifo nosso).

Os relatos denunciam que os conteúdos curriculares impostos pelo Sistema Oficial de Ensino não consideram as especificidades étnico-culturais das comunidades quilombolas, denotando uma concepção monocultural de currículo e de cultura escolar. Assim sendo, podemos deduzir que o pensamento da racionalidade ocidental, da monocultura do saber científico, é o modelo inspirador da concepção de conhecimento nas escolas (CANDAU, 2014). Essas constatações remetem às reflexões de Boaventura de Souza Santos (2010), que se contrapõe ao modo de pensar da racionalidade moderna e defende uma racionalidade mais ampla e cosmopolita. O autor apresenta a "ecologia de saberes" para criar uma nova maneira de relacionamento entre o conhecimento científico e outras formas de conhecimento. É necessário o trabalho de tradução, que é um procedimento capaz de criar inteligibilidade 
recíproca entre as experiências sociais disponíveis, que foram suprimidas e marginalizadas pelo paradigma da racionalidade moderna (sociologia das ausências) e as experiências sociais possíveis (sociologia das emergências), isto é, "o AINDA-NÃO”, mas existe como possibilidades (potencialidade) e capacidades (potência) (SANTOS, 2010). Nesse sentido, o currículo referendado pela "ecologia de saberes" certamente possibilitaria o diálogo intercultural entre os conhecimentos escolares e os saberes e as práticas das comunidades quilombolas.

Diante dessa perspectiva, compreendemos a diversidade como uma construção histórica, social e cultural das diferenças, a qual está imbricada com as relações de poder (GOMES, 2007). “[...] A questão da diversidade sociocultural diz respeito à formação teórica, de caráter histórico, antropológico e sociológico, mas também a processos complexos de opção ética e política dos profissionais e das instituições" (COSTA; MESSEDER, 2010, p. 11).

Assim, é imprescindível deslocar o currículo escolar das competências e habilidades técnicas, para compreendê-lo como um campo em que está em jogo vários elementos, implicados em relações de poder, de maneira que os professores possam trabalhar com as diferenças na escola (COSTA, 2005).

Esse cenário exige investimento na formação dos professores para trabalharem com a diversidade étnico-racial e cultural no contexto escolar. Isso significa "[...] abrir espaços que permitam a transformação da escola em um local em que as diferentes identidades são respeitadas e valorizadas, consideradas fatores enriquecedores da cidadania" (CANEN; XAVIER, 2011, p. 642).

Vale destacar que durante a pesquisa de campo, tanto em Brasileira como em Rio das Rãs, não presenciamos os professores realizarem planejamento de ensino nas escolas, dificultando a organização e a sistematização dos trabalhos, a troca e socialização das experiências, bem como a adaptação do currículo oficial ao contexto das comunidades. Em Araçá Cariacá, com a existência de horário de atividade complementar (AC) proporciona o planejamento de ensino, ainda que este se faça de forma individual, percebe-se certa organização e sistematização das atividades didáticas e pedagógicas, como foi constatado durante as entrevistas realizadas.
Segundo os professores, o poder público Municipal de Bom Jesus da Lapa não oferece formação docente inicial e nem continuada para o trabalho escolar com a diversidade étnico-racial e a Lei $n^{\circ} 10.639 / 03$ nas escolas, tampouco para o trato com as especificidades das comunidades quilombolas. Quando promove alguns cursos esporádicos, são para os docentes que lecionam História. Nesse sentido, os professores reivindicam formação específica para trabalharem nas escolas quilombolas. "Tem alguns cursos para os professores de História. Fala que vai ter essa formação continuada, só que fica no papel e não sai. Tem hora que começa e não termina" (DOCENTE 3, Escola Municipal Elgino Nunes de Souza, 06 de junho de 2013).

Compartilhando essa informação, outros professores argumentam:

Nunca ofereceu [curso] para gente aqui na comunidade. E os professores cobram isso, seria específico para a comunidade quilombola [...] (DOCENTE 3, Escola Municipal Quilombola Emiliano Joaquim Vilaça, 20 de maio de 2013).

A gente tem conhecimento por conta do curso da UNEB com a comunidade de Mangal e Barro Vermelho, Araçá Cariacá, reivindicação de Mangal Barro Vermelho, que parou e não deu continuidade [...] (DOCENTE 1, Escola Municipal Araçá Cariacá, 10 de abril de 2013).

Outra professora reforça a importância desse curso de capacitação, ofertado pela UNEB para as comunidades quilombolas de Mangal/Barro Vermelho e Araçá Cariacá: “[...] O curso serviu muito [...] os professores foram embora e aí acabou, mas foi muito proveitoso [...] Se retornasse esse curso para os professores novatos, para nós, seria bom demais, a UNEB juntamente com a Secretaria seria muito bom" (DOCENTE 2, Escola Municipal Araçá Cariacá, 11 de abril de 2013, grifo nosso).

O Projeto de Capacitação de Professores de Mangal/Barro Vermelho e Araçá Cariacá foi uma reivindicação dos líderes da Associação de Mangal/ Barro Vermelho feita ao Departamento de Ciências Humanas e Tecnologias (DCHT), Campus XVII, Bom Jesus da Lapa. Com a remoção dos professores formadores para outros campi da UNEB, o projeto foi desativado. 
Outro elemento que não favorece o trabalho com a questão racial e quilombola é a naturalização do preconceito e da discriminação racial. Os professores das três escolas veem os apelidos atribuídos aos alunos com traços de negritude mais ressaltados, pelo seu próprio grupo étnico-racial, como brincadeiras. Algumas falas remetem a esse problema: "Os meninos às vezes brincam, chamam os colegas de nego preto e macaco." (DOCENTE 5, Escola Municipal Araçá Cariacá, 24 de abril de 2013); “O seu cabelo não entra água, o seu cabelo é duro, esse tipo de brincadeira entre eles." (DOCENTE 3, Escola Municipal Quilombola Emiliano Joaquim Vilaça, 20 de maio de 2013); “Os alunos chamam os colegas de grafite, Bernardo e foguinho, de uma forma geral, a gente vê que é brincadeira." (DOCENTE 2, Escola Municipal Elgino Nunes de Souza, 06 de junho de 2013).

Para combater as atitudes preconceituosas e de discriminação racial presentes no cotidiano escolar, é necessário compreender que a questão racial brasileira se situa dentro do complexo campo da diversidade cultural (GOMES, 2005). Ademais, essa temática não deve ser tratada como tema transversal, nem tampouco algo apenas de interesse das pessoas pertencentes à população negra ou indígena: é uma questão social, cultural e política de toda a sociedade brasileira. O tratamento desta temática implica em uma reorganização epistemológica de tal ordem que todo o sistema de ensino se vê afetado, posto significar literalmente recontar a história de formação da sociedade brasileira, que tem imensa dificuldade de superar o mito das três raças e da sua decorrente democracia racial que a confortava como não racista. Portanto, a ruptura não é pequena e o trabalho é vasto, longo e mexerá nas estruturas profundas do poder colonizador interno.

A pesquisa aponta que o desconhecimento dos professores sobre as histórias e culturas das comunidades e sobre a Lei $\mathrm{n}^{\circ} 10.639 / 03$ e suas diretrizes correlatas dificulta o trabalho com a temática nas escolas, como podemos constatar: "Os professores que são de fora já vêm dizendo que não têm conhecimento [sobre essas questões] e aí vai passando" (DOCENTE 4, Escola Municipal Quilombola Emiliano Joaquim Vilaça, 22 de maio de 2013). Esse problema também aparece nas outras escolas:
Eu, na verdade, não conheço a história da comunidade. (DOCENTE 7, Escola Municipal Elgino Nunues de Souza, 11 de junho de 2013).

Conheço os relatos do dia que as lideranças vieram para a palestra. [...] O que fica mais para mim, é a questão da luta pelo reconhecimento da comunidade [como] quilombola, mas eu ainda sei pouco, preciso estudar mais. (DOCENTE 4, Escola Municipal Araçá Cariacá, 11 de abril de 2013).

$\mathrm{O}$ desconhecimento dos professores sobre a realidade das comunidades quilombolas onde atuam não é condição exclusiva dessas escolas. Muitos docentes, em diversas regiões do país, não conhecem, ou mantêm pouca relação, com as comunidades quilombolas onde trabalham, e por isso acabam desenvolvendo as suas práticas profissionais distantes do universo sociocultural dos alunos (BRASIL, 2012a). Essa realidade reforça a urgência de formação específica para os professores das escolas quilombolas, bem como para professores das escolas que atendem alunos oriundos desses territórios.

Nesse sentido, os cursos de formação necessitam de currículos flexíveis para que possam estabelecer diálogo com "[...] as especificidades da realidade histórica, política, econômica e sociocultural quilombola" (BRASIL, 2012a, p. 53). As diretrizes explicitam ainda a necessidade de formação dos coordenadores pedagógicos, bem como dos gestores das escolas e dos sistemas de ensino em regime de colaboração, para que a educação escolar quilombola seja implementada nos territórios quilombolas e nas escolas que atendem estudantes oriundos desses territórios.

Quanto ao conhecimento dos professores sobre o que tratam as Diretrizes Curriculares Nacionais para a Educação das Relações Étnico-Raciais, uma professora da Escola Municipal Elgino Nunes de Souza destaca: "Os professores sabem das Diretrizes, mas muitos não conhecem o que se discute no documento." (DOCENTE 6, Escola Municipal Elgino Nunes de Souza, 10 de junho de 2013). E em uma das escolas, segundo informação de duas professoras, não existem as Diretrizes para que os professores possam consultá-las. Acrescentamos ainda que todos os professores disseram que não conhecem as Diretrizes Curriculares Nacionais para 
a Educação Escolar Quilombola. Tal fato é compreensível, uma vez que essa legislação curricular, na época do trabalho de campo, havia sido editada há menos de seis meses.

A pesquisa ainda evidencia que a falta de coordenação pedagógica em duas das escolas, a insuficiência de materiais didáticos específicos, o comodismo e a resistência de alguns professores são elementos que não favorecem o trato pedagógico com a temática racial e os conteúdos históricos e culturais das comunidades.

Através dessas considerações expostas, podemos inferir que os professores encontram dificuldades para adaptar o currículo escolar ao universo sociocultural das comunidades, pois lhes faltam condições efetivas, tanto estruturais como pedagógicas, para a realização de suas atividades educativas, o que confirma que as práticas curriculares não dialogam com as especificidades étnico-culturais das comunidades. Desse modo, acabam reproduzindo uma concepção tradicional de educação, sem relação com o universo sociocultural dos educandos. Exceto em algumas atividades significativas, porém pontuais, que serão apresentadas no próximo tópico.

Ao analisarmos os Projetos Político-Pedagógicos de duas escolas, uma vez que na época da pesquisa de campo não encontramos este documento em uma delas, constatamos certa valorização das competências e habilidades de leitura e escrita e do raciocínio lógico-matemático, pouca referência às questões históricas e culturais das comunidades, bem como à história e cultura afro-brasileira. Vale acrescentar que a leitura, a escrita e a matemática não devem ser negligenciadas nas escolas, mas, sobretudo, articuladas ao trabalho com os saberes e os contextos locais.

Os dados coletados nos grupos focais com os alunos e as entrevistas com os pais e lideranças quilombolas locais reforçam que as questões históricas e culturais das comunidades são trabalhadas nas escolas de maneira esporádica, em datas comemorativas, eventos e gincanas, o que certamente não contribui para romper com as atitudes preconceituosas, discriminatórias e, consequentemente, estigmatizantes presentes nas escolas, como também para a afirmação das identidades quilombolas dos alunos.

\section{O trato pedagógico com a questão étnico-racial e quilombola: construindo novos significados}

As práticas pedagógicas não acontecem num movimento de linearidade, com comportamentos monolíticos, apresentando os mesmos sentidos e significados. Há indícios nas escolas pesquisadas de algumas práticas, embora pontuais, com a temática étnico-racial e quilombola, para além do componente curricular de História, que nos possibilitam refletir que as escolas também são lugares de resistências e de construção de novos significados (AMORIM; BATISTA NETO, 2011).

Em Araçá Cariacá, uma professora relatou alguns trabalhos que já desenvolveu na escola sobre a temática racial. Entre as atividades realizadas, sobre a história e a cultura da comunidade, uma oportunizou aos alunos pesquisarem no Relatório Técnico de Identificação e Delimitação do Território Quilombola da Volta e a outra, uma visita à Casa da Memória, como ela própria destaca:

Inclusive alguns alunos pesquisaram naquele livro antropológico ${ }^{6}$ da comunidade algumas questões que eu trabalhei em português, referentes à comunidade, e trouxeram até o livro [para a escola].

Nós fizemos uma pesquisa na escola e eu levei os alunos até à Casa da Memória, ${ }^{7}$ mostrei todas as coisas que tem lá e expliquei para eles. [...] Se você [perguntar aos/às alunos/as] do quarto ano, eles vão saber dizer o que tem na comunidade e o que eles viram na casa da memória. (DOCENTE 2, Escola Municipal Araçá Cariacá, 11 de abril de 2013).

Prosseguindo o diálogo, a professora destaca que organizou uma peça sobre a história da comunidade, com a participação dos alunos, a partir do trabalho com o livro Yoté: o jogo da nossa

6 O livro antropológico a que a professora se refere é o Relatório Técnico de Identificação e Delimitação do Território Quilombola da Volta, que envolve as Comunidades de Araçá, Cariacá, Coxos, Retiro, Pedras e Patos, de 2009.

7 A inauguração da casa da memória de Araçá Cariacá aconteceu em 16/11/2012, durante o Seminário das Comunidades Quilombolas do Território do Velho Chico e a IV Semana da Consciência Negra, realizado no período de 13 a 18 de novembro de 2012, coordenado pelo Departamento de Ciências Humanas e Tecnologias (DCHT) da Universidade do Estado da Bahia, Campus XVII de Bom Jesus da Lapa. A casa da memória na época da pesquisa de campo, em abril de 2013, ainda se encontrava em processo de estruturação. 
história, ${ }^{8}$ a qual contou também com a participação da comunidade e envolveu toda a escola. Cada professor ficou responsável por uma temática do livro que foi trabalhada em sala de aula. Relata a professora:

Nós fizemos uma peça colocando como foi que aconteceu [a história da comunidade], com os alunos representando o fazendeiro, Roque e a família de Roque. Eu fiquei a cargo de narrar o texto porque fui eu quem escreveu [a peça], eu narrava e os meninos iam apresentando. Trabalhamos primeiro na escola, depois nós apresentamos lá na Barrinha. ${ }^{9}$ [...] Inclusive a gente colocou não só alunos da escola, mas também pessoas da comunidade para participarem conosco [...] Foi muito proveitoso, ficamos muito felizes porque saiu da própria escola [...] A peça foi organizada com base no livro Yoté: jogo da nossa história [...] (DOCENTE 2, Escola Municipal Araçá Cariacá, 11 de abril de 2014, grifo nosso).

A professora continua discorrendo sobre outra atividade desenvolvida na escola:

O livro Estórias quilombolas, ${ }^{10}$ os meninos sabem de cor e salteado [...] têm as histórias de Santo, da onça, do homem que virava lobisomem, a gente já trabalhou com eles, os meninos já têm noção desses textos. A turma da tarde do fundamental I tem medo das histórias de assombração. [...] Eles leem os

8 Livro produzido pelo Instituto Agostin Castejon (Instituição filantrópica sem fins lucrativos). É um material didático formado pelo jogo africano Yoté, que pode ser praticado por duas ou mais pessoas. O jogo conta a vida e a obra de personagens brasileiros, como: Adhemar Ferreira, Chiquinha Gonzaga, Clementina de Jesus, Cruz e Souza, João Cândido, Lélia Gonzáles, Luiz Gama, Mãe Menininha, Mãe Senhora, Milton Santos, Pixinguinha e Zumbi dos Palmares. Além disso, no final do livro abre-se a possibilidade para o (a) aluno (a) incluir duas personagens da própria comunidade (uma mulher e um homem) e apresenta ainda uma variedade de atividades para os/as professores (as) trabalharem em sala de aula.

9 Todos os anos, no mês de novembro, os quilombolas do Território de Identidade do Velho Chico escolhem uma comunidade quilombola da região para realizar o evento em comemoração ao dia da Consciência Negra. As escolas quilombolas também são convidadas a participar deste evento.

10 Livro organizado por Glória Moura, da coleção Caminho das Pedras, volume III, contém estórias religiosas, de animais, de assombrações e mistérios, as quais foram narradas pelos remanescentes de quilombos do País. A obra é destinada aos/às alunos (as) do ensino fundamental e tem como objetivo contribuir para o desenvolvimento da autoestima dos moradores de quilombos, principalmente alunos (as) e professores (as) das comunidades quilombolas de Santa Rosa dos Pretos (MA), Mata do Tição (MG), Osório (RS) e Kalunga (GO). Essas estórias também têm como propósito auxiliar o trabalho com a Educação das relações étnico-raciais e a Lei ${ }^{\circ} 10.639 / 03$. textos e depois da leitura a gente faz perguntas com base nas historinhas e eles respondem. Eu trabalho mais em Português no fundamental I [ $4^{\circ}$ e $5^{\circ}$ ano]. (DOCENTE 2, Escola Municipal Araçá Cariacá, 11 de abril de 2013, grifo nosso).

Os relatos nos dão pistas de que a professora busca estabelecer diálogos entre os conteúdos escolares e as questões étnico-culturais e históricas da comunidade, a exemplo da pesquisa feita pelos alunos sobre a história e cultura da comunidade no Relatório Técnico de Identificação e Delimitação do Território Quilombola da Volta, a visita na Casa da Memória, como também o trabalho sistematizado a partir de leitura dos textos do livro Yoté: o jogo da nossa história, o qual contou com a participação de toda a escola e de membros da comunidade. A professora demonstra ter conhecimento da história, ficando responsável pela elaboração e narração da peça, como também do que trata em especial no livro Estórias Quilombolas, quando destaca que este livro contém estórias de assombração (histórias de que os/as alunos (as) do ensino fundamental I têm medo), estórias religiosas (de santo) e de mistérios (o homem que virava lobisomem). Contudo, não fica evidente se são feitas associações entre as estórias relatadas no livro e estórias que circulam na comunidade, tampouco quais interpretações são dadas para as estórias e por que os estudantes têm medo. Outro aspecto que não parece ser explorado é a própria existência de outras comunidades quilombolas, suas histórias, localização, lutas e o fato de haver livros didáticos e paradidáticos produzidos a partir dos saberes destas comunidades.

Vale ressaltar que essa professora participou, a convite das lideranças de Araçá Cariacá, do I Fórum de Educação Quilombola da Bahia, realizado em novembro de 2009 em Salvador. Neste evento a Coordenação da Diversidade SEC/BA distribuiu o livro Estórias quilombolas e quilombos: espaço de resistência de homens e mulheres negros para os professores que atuavam nas escolas em comunidades quilombolas e pesquisadores interessados na temática. Ademais, acrescente-se a essa informação que a professora também participou do Curso de Capacitação e Acompanhamento de Professores para as Comunidades Negras Rurais Quilombolas de Mangal/Barro Vermelho e de Araçá Cariacá. 
Em Brasileira, uma professora relata duas atividades realizadas com os alunos.

Agora mesmo, com o eixo de cidadania, eu peguei uma cartilhall dos povos tradicionais [os indígenas, os quilombolas, as comunidades de terreiro, os extrativistas, os ribeirinhos, os caboclos, os pescadores etc.], elaborei um questionário pra eles buscarem as respostas para poderem conhecer esses povos e as lutas de cada um. [...] Que leis garantem esses direitos ou não garantem. Então eu levei isso pra eles. Eu falei: 'Gente, é uma oportunidade que vocês têm de entender um pouco mais sobre essas questões de quilombos.' [...] Mas eu percebi, pelos trabalhos, que eles não conseguiram ler direitinho, nem todos os povos eles conseguiram destacar, as leis também é um pouco complexo, eu vi que eles não conseguiram colocar direito, mas é uma tentativa. (DOCENTE 4, Escola Municipal Quilombola Emiliano Joaquim Vilaça, 22 de maio de 2013, grifo nosso).

A professora sublinha que vai trabalhar novamente o conteúdo com os alunos. Importa considerar a necessidade de aulas dinâmicas, problematizadoras e contextualizadas para a participação e interação dos alunos no processo educativo e melhor aprendizagem "[...] sob o ponto de vista conceitual, além de uma postura ética diante do diverso e a construção de uma educação antirracista [...]" (GOMES, 2012, p. 15).

Vemos, na sequência do depoimento, como a professora evidencia certa sensibilidade e compromisso político com os problemas da comunidade.

Eu fiz uma palestra sobre a questão da história local, peguei várias fotos dos tempos anteriores e fui fazendo uma linha de tempo da história. Eu acho que foi legal, e a gente percebe, quando você conversa com os alunos, que eles já sabem falar um pouquinho, mesmo sem ter um trabalho tão elaborado e sistematizado, mas a gente tem trabalhado. Inclusive eu trouxe a memória de uma mulher lá do Capão do Cedro ${ }^{12}$ que sofreu muito [na época do conflito]. [...] Tem o depoimento dela chorando e eu levei pra sala de aula pra tá mostrando, até porque percebo que tem essa necessidade de tá falando pra eles [...] (DOCENTE 4, Escola Municipal Quilombola Emiliano Joaquim Vilaça, 22 de maio de 2013, grifo nosso).

11 Direitos dos povos e Comunidades Tradicionais, cartilha elaborada pela Secretaria de Promoção da Igualdade Racial em 2013.

12 Comunidade quilombola que faz parte do quilombo Rio das Rãs.
A professora parece reconhecer a necessidade de um trabalho mais sistematizado quando observa: "Eu acho que foi legal, e a gente percebe, quando você conversa com os alunos, que eles já sabem falar um pouquinho, mesmo sem ter um trabalho tão elaborado e sistematizado, mas a gente tem trabalhado". Assinala também que o trabalho com a história e cultura quilombola não pode ficar apenas sob a responsabilidade do professor de História, é preciso da participação de todos os docentes, para que os alunos "[...] aos poucos possam ir conhecendo mais e mais para então valorizar" esses conhecimentos locais. E arremata:

$\mathrm{Na}$ verdade, a gente tem um sonho que realmente essa questão da história [...] possa melhor ser trabalhada, para tá enriquecendo a afirmação desses futuros quilombolas, ${ }^{13}$ porque os que sofreram durante os conflitos ficaram bastante sensibilizados da necessidade da união, do respeito, do conhecer, do aceitar-se quilombola. [...] A gente percebe que os alunos, de uma forma geral, não estão mais neutros, mas ainda tem muito pra ser trabalhado, há essa necessidade. Porque eles no futuro é que vão segurar isso aqui [...] (DOCENTE 4, Escola Municipal Quilombola Emiliano Joaquim Vilaça, 22 de maio de 2013, grifo nosso).

Em Rio das Rãs, uma professora também relata como está trabalhando os conteúdos curriculares do livro Educação das Relações Étnico-Raciais do Fundamental II, que auxilia no ensino de História e Cultura Afro-Brasileira e Africana nas escolas:

A gente leva o livro para a sala e coloca os alunos para ler; de acordo a leitura eu vou explanando o conteúdo, colocando questões e eles voltam fazendo alguns questionamentos. Inclusive tem um texto que eu pedi pra eles construírem, uma árvore genealógica sobre os parentes. [...] Então, a gente traz a questão da família negra, a questão de como foi à escravidão. [...] Tem uma página que fala sobre os quilombos e um texto que cita como pai de Santo, o 'finado' Andrelino, ${ }^{14}$ cita sobre o quilombo Rio das

13 Expressa o sentido das crianças e jovens como futuras lideranças quilombolas da comunidade. Dito de outra maneira, a expressão parece sugerir uma espécie de ato falho, como se estas crianças e jovens ainda não tivessem se constituído como quilombolas plenos, ou seja, precisam incorporar a consciência política da sua própria condição, cuja introjeção se fará pelas relações comunitárias e ação pedagógica da escola.

14 O Sr. Andrelino Francisco Xavier foi um curador (já falecido) de Rio das Rãs muito conhecido na região, bastante respeitado e querido por todos do território quilombola (SILVA, 2010). 
Rãs, então a gente tem que [...] dizer para os alunos que é um orgulho essa cultura, é um orgulho a gente ser quilombola, pelo menos pra mim. (DOCENTE 4, Escola Municipal Elgino Nunes de Souza, 07 de junho de 2013, grifo nosso).

A professora abre o livro e aponta: "Aqui, na página 100, fala sobre o quilombo Rio das Rãs, já estudamos esse texto. Muitos alunos, devido à maneira como eu falo, acabam se empolgando [...]". Continuando com o relato, destaca: "Agora com o eixo temático, Identidade Cultural,,$^{15}$ estou trabalhando duas horas/aula por semana" e acrescenta: "Eu acho que a educação quilombola tinha que começar a partir da realidade dos alunos, deveria encaixar a realidade dentro dos livros de história deles" (DOCENTE 4, Escola Municipal Elgino Nunes de Souza, 07 de junho de 2013).

A professora trabalha de maneira dinâmica e contextualizada, busca estabelecer relação dos conteúdos escolares com a realidade dos alunos, possibilitando a participação ativa destes nas atividades realizadas. O envolvimento emotivo de sua condição de ser quilombola e da sua autoestima positiva certamente favorece o processo ensino-aprendizagem e influencia de maneira significativa a formação da identidade quilombola dos alunos.

Através dos elementos fornecidos por esses fragmentos de práticas de ensino, podemos inferir que as professoras reconhecem a importância de fazer dialogar os conteúdos curriculares com a realidade sociocultural e histórica das comunidades, e assim vêm "tentando" materializar esse propósito nas escolas. O esforço das professoras vai no sentido da reflexão de Freire (1997, p. 85-86, grifo do autor), ao assinalar que: "Não sou apenas objeto da História, mas seu sujeito igualmente. No mundo da História, da cultura, da política, constato não para me adaptar mas para mudar [...]". Todavia, cabe assinalar que, em que pesem algumas iniciativas positivas, de modo geral há um grande hiato entre o que se deseja para as escolas e o que se operacionaliza nas práticas curriculares.

15 Segundo informação de uma professora, esse eixo e o de cidadania [e consumo], como também os de leitura de rótulos [de embalagens] e recursos naturais foram incluídos, em 2013, nos currículos das escolas do município pela nova gestão da Secretaria Municipal de Educação, com o propósito de padronizar os componentes curriculares das escolas, para facilitar a transferência dos alunos de uma escola para outra.
Entendemos que sem a participação e o protagonismo das comunidades quilombolas, não há como pensar em educação escolar quilombola (LOPES, 2013; SILVA, 2013). Ao indagarmos às lideranças locais que educação escolar desejam para as suas comunidades, elas explicitam que a escola tem que ter "a cara do quilombo", isto é, elas reivindicam uma educação diferenciada, que além de trabalhar com matemática, história, geografia, português etc., inclua de forma efetiva no currículo, nos materiais didáticos e nas práticas educativas, a história, a cultura, os valores, os costumes, os saberes e o modo de vida de suas comunidades, como ilustram os relatos a seguir:

[...] A educação escolar quilombola não pode fazer só com o professor na sala de aula, o professor precisa buscar a comunidade [...] as pessoas idosas para trabalharem os valores [...] (LIDERANÇA QUILOMBOLA 2, Araçá Cariacá, 22 de abril de 2013).

A educação escolar tem que ter a cara do quilombo, e garantir também os conhecimentos de português, matemática, história, geografia, porque nós precisamos desse ensino que é o 'normal'. Mas nós precisamos do ensino que é o nosso jeito, que é a nossa cara, porque se isso não acontecer, nós não somos diferentes, tá entendendo? Existe aquele dizer: É proibido ser diferente? Não é. Então, nós queremos ser diferentes. (LIDERANÇA QUILOMBOLA 1, Brasileira, 16 de maio de 2013).

[É necessário] melhorar a qualidade do material didático e incluir a história e a cultura da comunidade no currículo escolar. [...] Falar de Chico Tomé, da história do avô dele, como funcionava antigamente o Mucambo, como funcionava o Retiro. Isso precisa ser registrado na escola para servir de material didático. (LIDERANÇA QUILOMBOLA 2, Brasileira, 16 de maio de 2013).

Vemos, através desses depoimentos, que as lideranças consideram importante que as escolas recorram às pessoas mais velhas das comunidades, para que possam compartilhar os seus conhecimentos, saberes, práticas e valores culturais, bem como incluir nos trabalhos educativos a memória de líderes locais que contribuíram com a luta e a história quilombola. Dessa forma, as escolas poderão contribuir de maneira significativa no processo de construção da identidade étnico-racial e da autoestima dos educandos (MACÊDO, 2008). 
Nesse processo educativo, os espaços localizados nas comunidades quilombolas, a exemplo da Casa da Memória (em Araçá Cariacá) e da casa de farinha (em Rio das Rãs), devem também ser apropriados e considerados pelas escolas como importantes ambientes de aprendizagens (ARRUTI; MAROUN; CARVALHO, 2011).

Diante dessas demandas, as escolas são convocadas a repensar o papel social, político e pedagógico da educação, tendo em vista descolonizar os currículos, para que possam construir práticas educativas interculturais, em diálogo com a realidade sociocultural e histórica das comunidades quilombolas. Ademais, os gestores e o Estado são obrigados a não verem os quilombolas como meros destinatários agradecidos da educação escolar em suas comunidades, mas como sujeitos de direitos e propositores de políticas para os seus territórios (ARROYO, 2014).

\section{Considerações finais}

Os professores reconhecem a necessidade de trabalhar os saberes tradicionais, as histórias e as culturas das comunidades quilombolas, porém não conseguem transgredir os currículos para ir além dos conteúdos impostos pelo Sistema Oficial de Ensino. Nesse sentido, podemos afirmar que as práticas curriculares das escolas não contemplam as especificidades étnico-culturais dos quilombolas. No entanto, constatamos algumas experiências significativas nas três escolas pesquisadas, de professoras quilombolas, ou que têm vínculos familiares com lideranças locais, que vêm transgredindo o currículo oficial e buscando outros significados, para aproximarem os conteúdos escolares do universo sociocultural dos alunos.

Diante desse contexto, é urgente superar as propostas de educação impostas às escolas quilombolas, para elaborar propostas curriculares, interculturais e diferenciadas, referendadas pela "ecologia de saberes", partindo de dentro das comunidades quilombolas, de maneira que os conteúdos escolares dialoguem com os saberes e as práticas desses sujeitos.

Essas demandas exigem que a gestão das escolas seja autônoma e democrática, para que possa criar espaços para o exercício de diálogos inter- culturais entre as escolas, as comunidades locais e as suas lideranças. Além do mais, a Secretaria Municipal de Educação deve oferecer às escolas assistência técnica, financeira e pedagógica para a elaboração, a execução e a avaliação de suas propostas de educação.

A educação escolar quilombola requer mudanças epistemológicas, políticas e culturais profundas no campo da educação, com implicações para a gestão das escolas e dos sistemas de ensino, para os currículos, os materiais didáticos, as práticas educativas e as políticas públicas de formação de professores. Nesse sentido, é imperativo que o Sistema Municipal de Ensino invista em políticas públicas específicas de formação docente, tendo como parâmetro as Diretrizes Curriculares Nacionais para a Educação Escolar Quilombola. A exemplo das escolas indígenas, defendemos a criação e a implementação de Cursos de Licenciatura Intercultural em Educação Escolar Quilombola (LICEEQ) para os professores que atuam nas escolas quilombolas e nas escolas que atendem estudantes oriundos desses territórios. É importante que essas políticas de formação se estendam também aos gestores das escolas e dos sistemas de ensino e aos coordenadores de área e coordenadores pedagógicos. Essa empreitada exige trabalho em regime de colaboração entre os entes federados (Município, Estado, Distrito Federal e União), bem como a vontade política dos governantes e a mobilização de toda sociedade civil.

Supõe, também, como em todo diálogo intercultural, que as partes envolvidas estabeleçam seus debates internos, ou seja, no âmbito dos sistemas de ensino (e aqui se trata dos professores e gestores da educação básica e da universidade), os atores devem promover uma intensa reflexão sobre suas próprias relações com as políticas afirmativas e o significado do racismo institucional. Por outro lado, as comunidades quilombolas devem discutir os seus próprios dilemas identitários, culturais e políticos. Como preconiza Appadurai (2009), a interculturalidade é um processo tenso entre alteridades que devem estar conscientes dos riscos da experiência dialógica que este exercício implica.

A caminhada é longa, há muito o que se fazer para que possa garantir de fato uma educação 
diferenciada para os quilombolas do Território de Identidade do Velho Chico, como também melhorar as condições materiais de vida no que tange à infraestrutura, transportes, saúde, estradas, comunicação, regularização fundiária, geração de rendas, desenvolvimento sustentável, entre outros bens e serviços sociais, para que os quilombolas sejam incorporados à sociedade nacional de maneira efetivamente mais simétrica e possam gozar da plena cidadania e de seus direitos à diferença.

\section{REFERÊNCIAS}

AMORIM, Roseane Maria de; BATISTA NETO, José. As práticas curriculares em uma escola da rede municipal do Recife: os fios e trama da educação das relações étnico-raciais no cotidiano escolar. Revista Lugares de Educação, Bananeiras, PB, v. 1, n. 2, p. 288-310, jul./dez. 2011. Disponível em: <http://periodicos.ufpb.br/ojs2/index. php/rle>. Acesso em: 8 ago. 2014.

APPADURAI, Arjun. Diálogo, risco e convivialidade. In: APPADURAI, Arjun. Et al. Podemos viver sem o outro? As possibilidades e os limites da interculturalidade. Lisboa: Fundação Calouste Gulbekian, 2009. p. 21-38.

ARROYO, Miguel Gonzalez. Outros sujeitos, outras pedagogias. 2. ed. Petrópolis, RJ: Vozes, 2014.

Currículo, território em disputa. 2. ed. Petrópolis, RJ: Vozes, 2011.

ARRUTI, José Maurício; MAROUN, Kaila; CARVALHO, Ediléia. Educação quilombola em debate: a escola em Campinho da Independência (RJ) e a proposta de uma Pedagogia Quilombola. In: CUNHA, Ana Stela de Almeida (Org.). Construindo Quilombos, desconstruindo mitos: a educação formal e a realidade quilombola no Brasil. São Luís: SETAGRAF, 2011. p. 29-43.

BRASIL. Secretaria de Educação. Conselho Estadual de Educação. Resolução no 68, de 30 de julho de 2013. Estabelece normas complementares para implantação e funcionamento das Diretrizes Curriculares Nacionais para a Educação Escolar Quilombola na Educação Básica, no Sistema Estadual de Ensino da Bahia. Diário Oficial do Estado da Bahia, Poder Executivo, Salvador, Bahia, 20 dez. 2013. Ano XCVIII, nº 21.316.

Presidência da República. Casa Civil. Lei no 10.639, de 09 de janeiro de 2003. Altera a Lei no 9.394, de 20

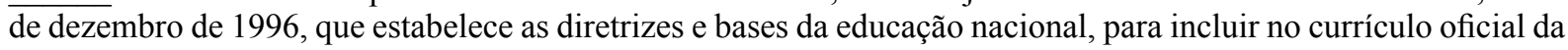
Rede de Ensino a obrigatoriedade da temática "História e Cultura Afro-Brasileira", e dá outras providências. Brasília, DF, 2003. Disponível em: <http://www.planalto.gov.br/ccivil_03/leis/2003/110.639.htm>. Acesso em: 30 maio 2013.

Presidência da República. Casa Civil. Lei n 11.645, de 10 de março de 2008. Altera a Lei no 9.394, de 20 de dezembro de 1996, modificada pela Lei no 10.639, de 9 de janeiro de 2003, que estabelece as diretrizes e bases da educação nacional, para incluir no currículo oficial da rede de ensino a obrigatoriedade da temática "História e Cultura Afro-Brasileira e Indígena. Brasília, DF, 2008. Disponível em: <http://www.planalto.gov.br/ ccivil_03/_ato2007-2010/2008/lei/111645.htm>. Acesso em: 30 maio 2013.

Ministério da Educação. Conselho Nacional de Educação. Câmara de Educação Básica. Parecer CNE/ $\overline{\mathrm{CEB} \mathrm{n}}{ }^{\circ}$ 16, de 05 jun. 2012. Institui as Diretrizes Curriculares Nacionais para a Educação Escolar Quilombola. Diário Oficial [da] República Federativa do Brasil, Poder Executivo, Brasília, DF, 20 nov. 2012a. Seção 1, p. 8.

. Ministério da Educação. Conselho Nacional de Educação. Câmara de Educação Básica. Resolução CNE/ $\overline{\mathrm{CEB} \mathrm{n}^{\circ}}$ 8, de 20 de novembro de 2012. Define as Diretrizes Curriculares Nacionais para a Educação Escolar Quilombola na Educação Básica. Diário Oficial [da] República Federativa do Brasil, Poder Executivo, Brasília, DF, 21 dez. 2012b. Seção 1, p. 26-30.

BRANDÃO. Carlos R. O que é educação. 49. ed. São Paulo: Brasiliense, 2007.

CANDAU, Vera Maria. Educação intercultural; entre afirmações e desafios: In: MOREIRA, Antonio Flavio; CANDAU, Vera Maria (Org.). Currículos, disciplinas escolares e culturas. Petrópolis, RJ: Vozes, 2014. p. $23-41$.

CANEN, Ana; XAVIER, Giseli Pereli de Moura. Formação continuada de professores para a diversidade cultural: ênfases, silêncios e perspectivas. Revista Brasileira de Educação, v. 16, n. 48, p. 641- 661, set./dez. 2011.

COSTA, Lívia Alessandra Fialho; MESSEDER, Marcos Luciano Lopes (Org.). Educação, multiculturalismo e diversidade. Salvador: EDUFBA, 2010. 
COSTA, Marisa Vorraber. Currículo e política cultural. In: neos. 4. ed. Rio de Janeiro: DP\&A, 2005. p. 37-68.

(Org.). O currículo nos limiares contemporâ-

CRUZ, Carcius Marcelus. Trajetórias, lugares e encruzilhadas na construção da política de educação escolar quilombola no Paraná no início do III milênio. 2012. 197f. Dissertação (Mestrado em Educação) - Universidade Federal do Paraná, Curitiba, 2012.

FREIRE, Paulo. Pedagogia da autonomia: saberes necessários à prática docente. 4. ed. São Paulo: Paz e Terra, 1997.

GOMES, Nilma Lino. Alguns termos e conceitos presentes no debate sobre relações raciais no Brasil: uma breve discussão. In: MINISTÉRIO DA EDUCAÇÃO (Org.). Educação anti-racista: caminhos abertos pela Lei Federal $\mathrm{n}^{\circ}$ 10.639/03. Brasília, DF, 2007. p. 39-62.

Indagações sobre currículo: diversidade e currículo. In: BEAUCHAMP, Jeanete; PAGEL, Sandra Denise; NASCIMENTO, Aricélia Ribeiro do. Brasília, DF: Ministério da Educação/Secretaria de Educação Básica, 2005. p. $17-47$.

Apresentação. In: GOMES, Nilma Lino (Org.). Práticas pedagógicas de trabalho com relações étnico-raciais na escola na perspectiva da Lei $\mathbf{n}^{\mathbf{0}}$ 10.639/03. Brasília: MEC/Unesco, 2012. p. 7-16.

GUSMÃO, Neusa Maria Mendes de. Antropologia, diversidade e educação: um campo de possibilidades. Ponto-e-vírgula, n. 10, p. 32-45, 2011. Disponível em: <file://C:/Users/New\%20Drive/Downloads/13898-33520-1-SM. pdf>. Acesso em: 26 jun. 2017.

LOPES, Dilmar Luiz. Rodas de conversa e educação escolar quilombola: arte do falar e saber fazer. 2013. $253 \mathrm{f}$. Tese (Doutorado em Educação) - Universidade Federal do Rio Grande do Sul, Porto Alegre, 2013.

MACÊDO, Dinalva de Jesus Santana. O currículo escolar e a construção da identidade étnico-racial da criança e do adolescente quilombola: um olhar reflexivo sobre a auto-estima. 2008. 144f. Dissertação (Mestrado em Educação e Contemporaneidade) - Universidade do Estado da Bahia, Salvador, 2008.

Educação em Comunidades Quilombolas do Território de Identidade do Velho Chico/BA: indagações acerca do diálogo entre as escolas e as comunidades locais, 2015, 217 f. Tese (Doutorado em Educação e Contemporaneidade) - Universidade do Estado da Bahia, Salvador, Bahia, 2015.

MUNANGA, Kabengele. A questão da diversidade e da política de reconhecimento das diferenças. Crítica e Sociedade v. 4, n. 1, p. 34-45 jul. 2014. Disponível em: <http://www.seer.ufu.br/index.php/criticasociedade/article/ viewFile/26989/14725>. Acesso em: 20 jul. 2014.

OLIVEIRA, Suely Noronha de. Diretrizes curriculares para a educação escolar quilombola: o caso da Bahia e o contexto nacional. 2013. 232f. Dissertação (Mestrado em Educação) - Pontifícia Universidade Católica do Rio de Janeiro, Rio de Janeiro, 2013.

SACRISTÁN, J. Gimeno. Currículo e diversidade cultural. In: SILVA, Tomaz Tadeu da; MOREIRA, Antônio Flávio (Org.). Territórios contestados: o currículo e os novos mapas políticos e culturais. 3. ed. Petrópolis, RJ: Vozes, 1999. p. 82-113.

SANTOMÉ, Jurgo Torres. As culturas negadas e silenciadas no currículo. In: SILVA, Tomaz Tadeu da (Org.). Alienígenas na sala de aula. 6. ed. Petrópolis, RJ: Vozes, 2005. p. 159-177.

SANTOS, Boaventura de Souza. Para além do pensamento abissal: das linhas globais a uma ecologia de saberes. Revista Crítica de Ciências Sociais, n. 78, p. 3-46, out. 2007.

A gramática do tempo: para uma nova cultura política. 3. ed. São Paulo: Cortez, 2010.

SILVA, Paulo Sérgio da. Contornos pedagógicos de uma educação escolar quilombola. 2013. 260f. Tese (Doutorado em Educação) - Universidade Federal do Rio Grande do Sul, Porto Alegre, 2013.

SILVA, Valdélio Santos. Rio das Rãs e Mangal: feitiçaria e poder em territórios quilombolas do Médio São Francisco. 2010. 354f. Tese (Doutorado em Estudos Étnicos e Africanos) - Programa Multidisciplinar em Estudos Étnicos e Africanos da Universidade Federal da Bahia, Salvador, 2010.

Recebido em: 01/04/2017

Aprovado em: 02/07/2017 